\title{
Morphological Change During The Ontogeny Of The Planktic Foraminifera
}

\author{
Aude G. M. Caromel*, Daniela N. Schmidt, Ian Fletcher \& Emily J. Rayfield \\ School of Earth Sciences, University of Bristol, Wills Memorial Building, Queens Road, Bristol BS8 1RJ, UK \\ *Correspondence: ac3545.2003@my.bristol.ac.uk
}

\begin{abstract}
Development plays an important part in shaping adult morphology and morphological disparity, yet its influence on evolutionary processes is seldom explored because of a lack of preservation of ontogenetic stages in the fossil record. By preserving their entire ontogenetic history within their test, and with the advent of high-resolution imaging techniques, planktic foraminifera allow us to investigate the influence of developmental constraints on disparity. Using Synchrotron radiation X-ray tomographic microscopy (SRXTM), we reconstruct the ontogenetic progression of seven species across several of the major morphotypic groups of planktic foraminifera, including morphotypes of a species exhibiting high phenotypic plasticity and closely related pseudo-cryptic sister-taxa. We show differences in growth patterns between the globigerinid species, which appear more tightly regulated within the framework of isometry from the neanic stage, and the globorotaliid species, whose adult stages present allometric trends. Morphological change through ontogeny results in a change in surface area to volume ratios. Different metabolic processes therefore dominate at different stages of ontogeny, changing the vulnerability of the organism to environmental influences over growth, from factors affecting diffusion rates in the juvenile to those affecting energy supply in the adult. These findings identify some of the parameters within which evolutionary mechanisms have to act.
\end{abstract}

Keywords: planktic foraminifera; ontogeny; Synchrotron radiation X-ray tomographic microscopy; growth patterns; surface area to volume ratio

Received 16 June 2014; accepted 10 February 2015

Studies of morphological disparity in fossil groups are often restricted to using adult forms, due to the fragmentary nature of the fossil record and the difficulty in obtaining complete ontogenetic sequences (e.g. Gerber et al. 2008). Yet exclusively considering adult forms ignores the important role that developmental constraints play in the evolutionary process (Gerber et al. 2008). The concept of heterochrony, changes in the rate or timing of developmental events relative to the same events in the ancestor (Alberch et al. 1979), is a prime example of the importance of characterizing morphology throughout development to understand the processes leading to evolutionary change. In the ocean, mechanisms behind morphological evolution and speciation remain particularly elusive. The seemingly restricted variety of resources in the ecosystems and apparent lack of geographical or hydrographical barriers to gene flow (Hutchinson 1961; Palumbi 1994; Roy \& Chattopadhyay 2007) make temporal and spatial effects likely drivers of isolation and evolutionary change through sympatric or parapatric speciation (Norris 2000; Roy \& Chattopadhyay 2007). It is, therefore, essential to understand how the environment interacts with intrinsic constraints over the development of an organism to generate new forms.

Planktic foraminifera provide excellent material to investigate the influence of development on morphological disparity, as they grow by the sequential accretion of chambers on to their test. Consequently, each successive stage of growth remains an integral part of the growing structure (Huang 1981), occasionally accompanied by additional overgrowth, thickening, or selective resorption of previously deposited calcite (Hemleben et al. 1989). Biometric studies incorporating environmental information in this group have demonstrated a close relationship between morphology and environmental parameters, such as temperature, salinity and nutrient fluctuations, both in the fossil record and in the modern ocean (Hecht \& Savin 1972; Hecht 1974; Healy-Williams 1989;
Renaud \& Schmidt 2003; Schmidt et al. 2004). At an individual level, the environment has been shown, through culturing experiments (e.g. Bé et al. 1981; Hemleben et al. 1987; Bijma et al. 1990), to drive morphotypic variability by phenotypic plasticity (where different morphologies are generated from a single genotype as a direct result of variations in environmental parameters; Schlichting \& Smith 2002). At the population level, however, molecular analyses of living species have shown that many recognized morphospecies each comprise several distinct genetic entities, often with separate ecologies and biogeographical distributions (Huber et al. 1997; Darling et al. 1999; de Vargas et al. 2001; Renaud \& Schmidt 2003; Darling \& Wade 2008).

A number of studies have qualitatively described the ontogeny of several planktic foraminiferal species (e.g. Bé et al. 1969; Huang 1981; Sverdlove \& Bé 1985; Brummer et al. 1986, 1987; Huber 1994), leading to the definition of a five-stage model of growth in the globigerinids (Brummer et al. 1987). Growth begins with the prolocular stage, followed by the juvenile stage from the deuteroconch onwards, which is characterized by the addition of a number of chambers of uniform morphology (Brummer et al. 1987). The neanic stage is initiated by abrupt overall morphological changes and represents a rapid, gradual transition towards the adult morphology, marked by changes in chamber shape, umbilical reduction and aperture position (Brummer et al. 1987). These continue throughout the adult stage, maturity signalled by the addition of minor but often distinct features, such as secondary apertures and further modifications in chamber shape and coiling (Brummer et al. 1987). Growth is terminated by gametogenesis and the formation of one or two chambers highly variable in shape in the terminal stage (Brummer et al. 1987).

The previous investigations into the interior of planktic foraminifera relied on a combination of low-resolution X-ray microscopy (Bé et al. 1969), scanning and transmission electron 
microscopy (Sverdlove \& Bé 1985; Brummer et al. 1986, 1987) and serial dissection (e.g. Huber 1994) to reveal ontogenetic changes in morphology. Such methods, however, restrict our ability to resolve details of the morphology in three-dimensions and accurately quantify interior proportions, due to the overlapping nature of foraminiferal growth. New technologies, such as computed tomography, allow us to overcome these problems, as demonstrated by the quantification of internal cavity volumes of a benthic foraminiferal species (Speijer et al. 2008). Following Schmidt et al. (2013), we use Synchrotron radiation X-ray tomographic microscopy (SRXTM) to reveal features of the internal morphology of microfossils without destroying the specimens (Donoghue et al. 2006). Here we quantify the ontogenetic progression of morphology in seven species of planktic foraminifera across a spectrum of different morphologies. We assess mechanisms of growth and morphological diversity within the group through ontogeny and aim to identify potential causes of variability and constraints thereon.

\section{Materials and methods}

\section{Specimen selection}

Eight specimens representing seven species were chosen for imaging and analysis across the globigerine (spinose) and globorotaliid (non-spinose) groups, representing some of the main morphologies in the planktic foraminifera: Globigerina bulloides (d'Orbigny); Globigerinoides sacculifer (Brady) morphotypes with and without sac-like final chamber (herein referred to as 'sacculifer' and 'trilobus' morphotypes, respectively); pseudo-cryptic sister-taxa Globigerinella siphonifera (d'Orbigny) and Globigerinella radians (Egger), identified on the basis of symbionts respectively as Globigerinella siphonifera types II and I as per Huber et al. (1997) and reassigned according to Weiner et al. (2015); Globorotalia menardii (d'Orbigny); Globorotalia tumida (Brady); and Globorotalia truncatulinoides (d'Orbigny).

In the globigerines, Globigerina bulloides arose in the midMiocene and is descended from Subbotina roesnaensis via G. officinalis and G. praebulloides (Aze et al. 2011). Globigerinella siphonifera and, by extension, sister-taxon Gll. radians, originated in the early Pliocene, evolving from G. praebulloides in the early Oligocene via G. praesiphonifera and G. obesa (Aze et al. 2011). Globigerinoides sacculifer arose in the early Miocene from a separate Subbotina lineage that originated in the early Paleocene (Aze et al. 2011).

Globorotaliid Globorotalia menardii is descended from $G$. (H.) praescitula via $G$. (M.) archeomenardii and $G$. (M.) praemenardii in the mid-Miocene, and Gr. tumida arose in the late Miocene from Gr. menardii via G. merotumida and G. plesiotumida (Aze et al. 2011). Globorotalia truncatulinoides is descended from $G$. (H.) praescitula in a separate lineage arising in the mid-Miocene via $G$. (H.) scitula and G. (H.) cibaoensis and culminating in Gr. truncatulinoides in the late Pliocene (Aze et al. 2011).

The provenance of each specimen scanned is shown in Table 1. For each species, a specimen that was well preserved and representative of the adult morphology (non-aberrant), having undergone full ontogenetic growth to the adult stage, was chosen for imaging.

\section{Specimen preparation and scanning}

Specimens were either directly mounted on $3 \mathrm{~mm}$ brass stubs using a small amount of PVA glue, or deposited in a glass capillary tube mounted on the stub with a drop of wax.

SRXTM was performed at the TOMCAT beamline (Stampanoni et al. 2006) tomography station at the Swiss Light Source, Paul Scherrer Institut, Villigen, Switzerland. The X-ray beam energy, microscope magnification, binning and resulting isotropic voxel dimensions for each specimen are presented in Table 1. The X-ray beam energy was optimized for maximum contrast between the materials composing the samples. Binning, though it decreases resolution by combining four adjacent pixels into a single pixel, decreases data processing time and increases sensitivity to light, improving the signal-to-noise ratio.

The radiographic projections of the specimens were acquired under different angular views over a range of $180^{\circ}$, post-processed and rearranged into flat and darkfield corrected sinograms visually representing the raw radiographic data. These sinograms were then reconstructed on-site using optimized filtered back-projection routines to create a volume set of section images (tomograms) stored as 8-bit Tagged Image File Format (TIFF).

\section{D model generation}

Slice data from the scans were imported into the $3 \mathrm{D}$ visualization and reconstruction software Avizo 6.3 (Mercury Computer Systems Ltd, Chelmsford, MA, USA, www.tgs.com) for analysis. As pixels are assigned a grey-scale value in post-processing to represent the different X-ray attenuation properties of the materials making up the sample, the calcite test of the foraminiferal specimen could be isolated from the mounting apparatus and any residual sediment infilling and organic matter. Due to the homogeneous nature of the calcite within the test resulting in similar attenuation throughout the specimen, segmentation of the individual chambers was carried out manually using three orthogonally recreated stacks of slices through the specimen.

Each chamber was labelled as a different element to create each ontogenetic step as an independent unit, as far as selective dissolution, remodelling and overgrowth could allow. The successive layers of calcite deposited over the entire external surface of the test in the formation of each new chamber during bilamellar growth, as well as the layer of gametogenic calcite in certain species (Bé \& Lott 1964; Lipps 1973), were indistinguishable from the original chamber in the SRXTM scans. It was, therefore, neither possible to clearly identify the original chamber boundaries, nor to separate the layers of overgrowth into individual deposition increments. To circumvent this limitation, boundaries between successive chambers were defined by a straight line connecting the inner and outer suture between two chambers, and any calcite overgrowth or successive layers were consequently assigned to the chamber they cover, based on extrapolations from the internal chamber sutures. In the earlier ontogenetic steps of $G d$. sacculifer 'sacculifer' morphotype, Gr. truncatulinoides, Gr. tumida and G. bulloides, where the layer corresponding to the primary organic membrane during deposition was visible, the inner part of the chamber was isolated from the later overgrowth as a separate element for chamber shape visualization and photography only. The internal cavity of each chamber was also manually isolated (incorporating any residual sediment or organic infilling, to represent the true internal space) and assigned to separate elements for volumetric estimation. Each element was rendered as a three-dimensional surface for measurement and visualization of each ontogenetic step. Note that we use the term 'ontogenetic step' to define addition of a new chamber at any point of ontogeny, whereas 'ontogenetic stage' refers to any of the five stages of the ontogenetic concept outlined by Brummer et al. (1987).

\section{Morphometric measurements}

With specimens oriented with each newly built chamber at the top, length and height measurements of the overall test and the isolated chamber at each ontogenetic step were taken in lateral view, i.e. orthogonal to the spiral view. Height was measured orthogonal to length, as the distance between two lines running parallel to length 
Table 1. Age, provenance and Synchrotron radiation X-ray tomographic microscopy specifications for each of the specimens scanned

\begin{tabular}{|c|c|c|c|c|c|c|}
\hline Species & Age and provenance & $\begin{array}{l}\text { X-ray beam } \\
\text { energy }(\mathrm{keV})\end{array}$ & $\begin{array}{l}\text { X-ray microscope } \\
\text { magnification }\end{array}$ & $\begin{array}{l}\text { Binning of } \\
\text { pixels }\end{array}$ & $\begin{array}{l}\text { Isotropic voxel } \\
\text { size }(\mu \mathrm{m})\end{array}$ & $\begin{array}{l}\text { No. of } \\
\text { slices }\end{array}$ \\
\hline $\begin{array}{l}\text { Globigerina } \\
\text { bulloides }\end{array}$ & $\begin{array}{l}\text { Holocene, sediment sample, west coast of South } \\
\text { Africa, Walvis Ridge Transect (ODP Leg 208, site } \\
\text { 1264A-1H-1, 0-2 cm) }\end{array}$ & 9.87 & $\times 20$ & $\times 1$ & 0.35 & 929 \\
\hline $\begin{array}{l}\text { Globigerinoides } \\
\text { sacculifer, 'sacculifer' } \\
\text { morphotype }\end{array}$ & $\begin{array}{l}\text { Miocene-Pliocene boundary, sediment sample, } \\
\text { Caribbean (ODP Leg 165, site 1000A-20H-3, } \\
147-149 \mathrm{~cm})\end{array}$ & 9.87 & $\times 20$ & $\times 2$ & 0.7 & 577 \\
\hline $\begin{array}{l}\text { Globigerinoides } \\
\text { sacculifer, 'trilobus' } \\
\text { morphotype }\end{array}$ & $\begin{array}{l}\text { Holocene, sediment sample, west coast of South } \\
\text { Africa, Walvis Ridge Transect (ODP Leg 208, site } \\
\text { 1264A-1H-1, 0-2 cm) }\end{array}$ & 17.5 & $\times 10$ & $\times 2$ & 1.4 & 427 \\
\hline $\begin{array}{l}\text { Globigerinella } \\
\text { siphonifera and } \\
\text { Globigerinella } \\
\text { radians }\end{array}$ & $\begin{array}{l}\text { Recent, surface water sample, SCUBA collected by } \\
\text { Brian Huber and Jelle Bijma off coast of Curaçao }\end{array}$ & 15 & $\times 20$ & $\times 1$ & 0.35 & 1259 \\
\hline $\begin{array}{l}\text { Globorotalia } \\
\text { menardii }\end{array}$ & $\begin{array}{l}\text { Holocene, sediment sample, west coast of South } \\
\text { Africa, Walvis Ridge Transect (ODP Leg 208, site } \\
\text { 1264A-1H-1, 0-2 cm) }\end{array}$ & 17.5 & $\times 10$ & $\times 2$ & 1.4 & 200 \\
\hline $\begin{array}{l}\text { Globorotalia } \\
\text { truncatulinoides }\end{array}$ & $\begin{array}{l}\text { Holocene, sediment sample, NW coast of Africa (RV } \\
\text { Meteor cruise, core sample GeoB1802-10, } 0-1 \mathrm{~cm})\end{array}$ & 15 & $\times 20$ & $\times 1$ & 0.35 & 1541 \\
\hline Globorotalia tumida & $\begin{array}{l}\text { Pliocene, sediment sample, west of Panama Isthmus, } \\
\text { SE Pacific Transect (ODP Leg 202, site 1241A-8H-2, } \\
10-12 \mathrm{~cm} \text { ) }\end{array}$ & 9.87 & $\times 20$ & $\times 2$ & 0.7 & 747 \\
\hline
\end{tabular}

through the outermost points on the outline. Test surface area and volume, and chamber internal volume were extracted from the software.

\section{Results - ontogenetic descriptions}

Globigerina bulloides ( $\mathrm{Pl}$. 1). The specimen consists of 14 chambers arranged over three dextrally coiling whorls. Measuring $20 \mu \mathrm{m}$ by $25 \mu \mathrm{m}$, the proloculus is ovoid in shape and atypically large for a spinose species, as recognized previously by Sverdlove \& Bé (1985). The common wall with the deuteroconch is flat, as noted in other globigerinids by Brummer et al. (1987), and the deuteroconch and 3rd chamber are smaller than the proloculus. Chambers are globular, leading to radial sutures between successive chambers in spiral view. They are arranged in the juvenile stage in a low trochospire with a flattened spiral side and a broad umbilicus, leading to a lobate outline which is maintained throughout growth. A low-arched aperture is visible from the deuteroconch onwards and positioned extra-umbilically. It becomes more arched at chamber 5, as the chambers begin to cover the umbilicus.

The neanic stage begins with the 8th chamber, with a change in both chamber and overall test length growth curves (Fig. 1a, b) lagged by the test and chamber height at chamber 9 , and the progressive migration of the aperture to its final umbilical position. The chambers become more spherical (Fig. 1d) and the increasingly high trochospiral growth leads to a narrowing of the umbilicus. Possibly due to gametogenic resorption and overgrowth or recalcification, spines and pores, which are characteristic features used by Brummer et al. (1987) to identify later stage transitions, are not recognizable, although surface texture over the entire surface of chambers 10 and above could be interpreted as remnants of pores. Overall test height increases relative to length (Fig. 1c), due to the displacement of chamber accretion to a more umbilical position. This leads to a higher trochospire and, due to the closure of the umbilicus by the umbilical extension and overlap of the chambers, the formation of a pseudo-umbilicus. In the penultimate and antepenultimate chambers, the aperture acquires a low rim, which disappears in the final chamber.

Globigerinoides sacculifer, 'sacculifer' and 'trilobus' morphotypes (Pls 2 and 3; description and plate of Gd. sacculifer, 'trilobus' morphotype amended from Schmidt et al. 2013). The 'sacculifer' specimen contains 17 chambers in 3.5 dextrally coiling whorls, growing from a near-spherical proloculus roughly $20 \mu \mathrm{m}$ in diameter, to a maximum length of $568 \mu \mathrm{m}$. The first four chambers are similar in size to the proloculus, with the deuteroconch marginally smaller. The 'trilobus' specimen consists of 18 chambers, growing from a smaller proloculus $18 \mu \mathrm{m}$ in diameter to a final test length of $702 \mu \mathrm{m}$. The lower scan resolution of $1.4 \mu \mathrm{m}$ for the 'trilobus' specimen leads to pixellation of earlier chambers and poorer reconstruction of features such as aperture, pores and surface texture.

The juvenile chambers in both specimens are subquadrate in shape, being flattened spirally and extending umbilically, giving the early whorl an acute periphery. Chambers are arranged in a very low trochospire with a flattened, almost involute spiral side, such that the overall test has a plano-convex outline, as previously noted by Brummer et al. (1987). The sutures between the successive chambers are recurved in spiral view, indicating greater overlap of a newly accreted chamber on to the previous one. The aperture is visible from the deuteroconch onwards in the 'sacculifer' specimen, and is high-arching and positioned extra-umbilically. The onset of the neanic stage is preceded, from chamber 8 onwards, by the displacement of chamber accretion in an umbilical direction to cover more of the umbilicus in the 'sacculifer' specimen, and the inflation of chambers on the spiral side in the 'trilobus' specimen. The appearance of pores and surface texture on the spiral side occurs at, or just prior to, the transition to the next stage.

Loss of the acute periphery of the test, and a shift in overall shape to a lobate outline, occurs from chamber 10 in the 'sacculifer' specimen and chamber 12 in the 'trilobus' specimen, with a change in slope of the test length growth curve (Fig. 2a, b), marking the beginning of the neanic stage. The change in overall outline, however, with an increase in test height relative to test length (Fig. 2c), is not caused by a change in chamber dimensions (Fig. 2d), but is a result of the increasingly globular form of the chambers and their accretion in a more umbilical position, leading to the formation of a higher trochospire. As a consequence of the more rounded chambers and looser coiling, sutures between successive chambers become more radial. The neanic stage sees a progressive migration of the aperture to an umbilical position, and the formation of a fully cancellate texture appears with the creation of pores on the umbilical side in the later stages. 


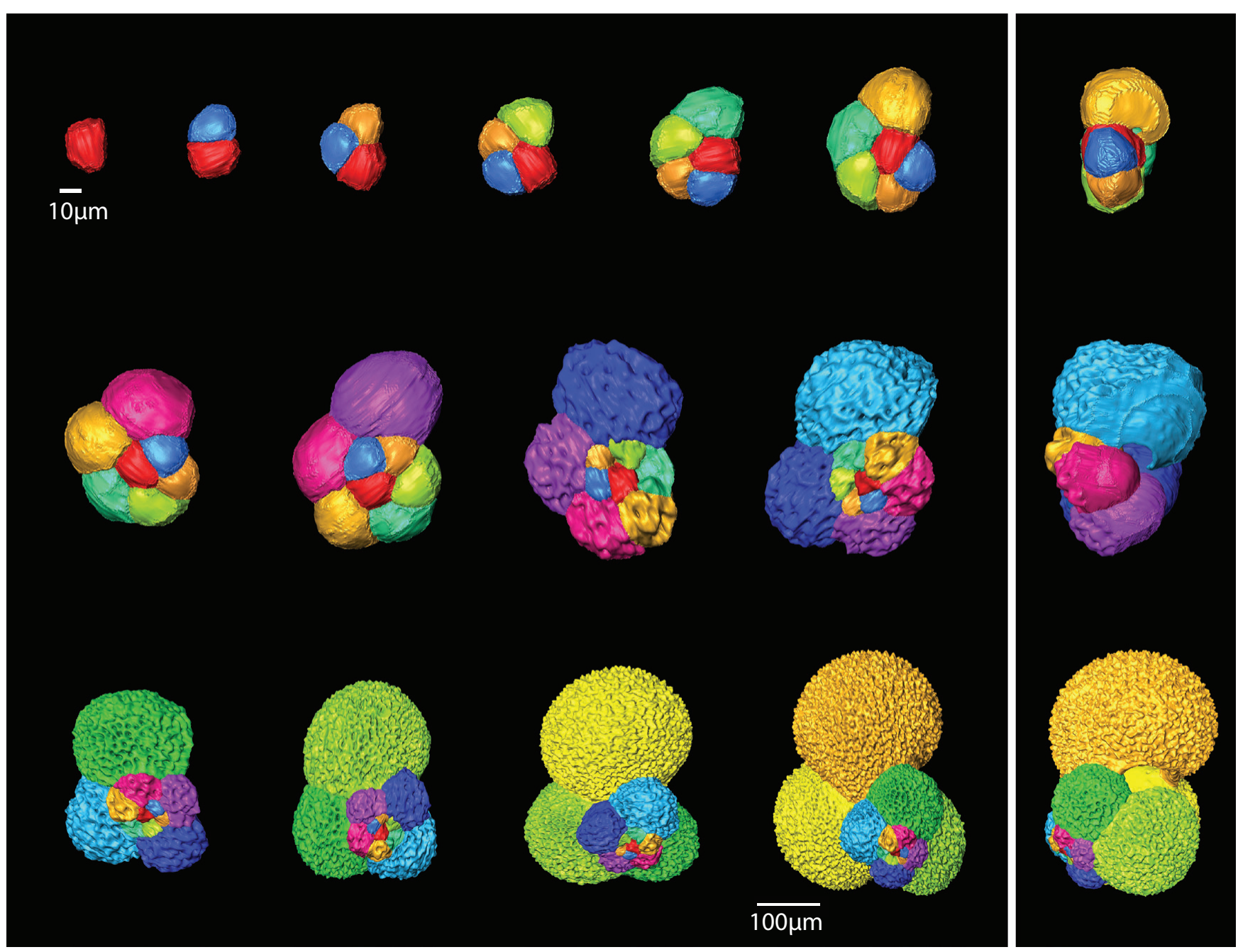

Explanation of Plate 1. 3D ontogenetic reconstruction of Globigerina bulloides from the proloculus (top left) to the terminal stage (bottom right).

The typical spherical chambers of the adult, coming with a greater increase in volume, begin the transition to the adult stage. It extends from chambers 14-17 in the 'sacculifer' specimen and chambers 16-18 in the 'trilobus' specimen, and is recognized by the appearance of secondary apertures on the spiral side, opposite to the main aperture and characteristic of the Globigerinoides genus. Growth is terminated in the 'sacculifer' specimen by the formation of a thinner-walled, sac-like chamber of smaller proportions than the penultimate, with large primary and secondary apertures bordered by a rim.

Globigerinella radians and GIl. siphonifera (Pls 4 and 5). The Gll. radians specimen is made up of 13 chambers in 2.5 whorls, and sinistrally coiled. The near-spherical proloculus $22 \mu \mathrm{m}$ in diameter is followed by a smaller deuteroconch. Also sinistrally coiled, the Gll. siphonifera specimen contains 16 chambers in 3 whorls. The proloculus is ovoid at $15 \mu \mathrm{m}$ by $22 \mu \mathrm{m}$. In the juvenile stages of both specimens, the aperture is high-arched and positioned extra-umbilically. Sutures between the successive chambers are radial in spiral view, as a result of loosely accreted, globular chambers. Whilst chambers are added in an umbilical direction in a very low trochospire, their low displacement and some chamber expansion over the spiral side of the test, give an illusion of planispiral growth. This is particularly true in the Gll. radians specimen, with chambers in the Gll. siphonifera specimen being more flattened on the spiral side and extended umbilically. The test outline is clearly lobate. Surface texture and the traces of pores become visible on the spiral side from chamber 5 in Gll. radians and chamber 8 in Gll. siphonifera. The first preserved spines can be seen at chamber 6 in Gll. siphonifera versus chamber 7 in Gll. radians.

In the Gll. radians specimen, progression to the neanic stage at chamber 7 is marked by the development of a thin rim on the margins of the aperture, and visible pores can be seen on the umbilical side at this stage. The concurrent change in growth trajectories marking the transition from juvenile to neanic stages is very slight (Fig. 3), reflecting a small shift of chamber addition in an umbilical direction, though growth is still in a low trochospiral and no closing over of the umbilicus occurs. A clear cancellate surface texture is established by chamber 9 . In the Gll. siphonifera specimen, the formation of the lip at the aperture and a slow closing off of the umbilicus from chamber 8 precedes the change in growth trajectories at chamber 10 marking the neanic stage (Fig. 3). More spherical chambers are accreted in a slightly higher trochospire leading to the formation of a pseudo-umbilicus.

The adult stage, comprising the final four chambers in Gll. radians and final five chambers in Gll. siphonifera, sees expansion and progressive migration of the aperture to a subequatorial position, and accretion of the chambers increasingly covering the midline of the previous whorl, leading to an involute appearance. In Gll. siphonifera, this is accompanied by a greater increase in chamber volume (Fig. 3e). The final chamber in Gll. siphonifera also departs in shape from the spherical by being more compressed in length.

Globorotalia menardii (Pl. 6; description and plate amended from Schmidt et al. 2013). The specimen is made up of 16 chambers in three whorls. The proloculus is spherical with a diameter of 

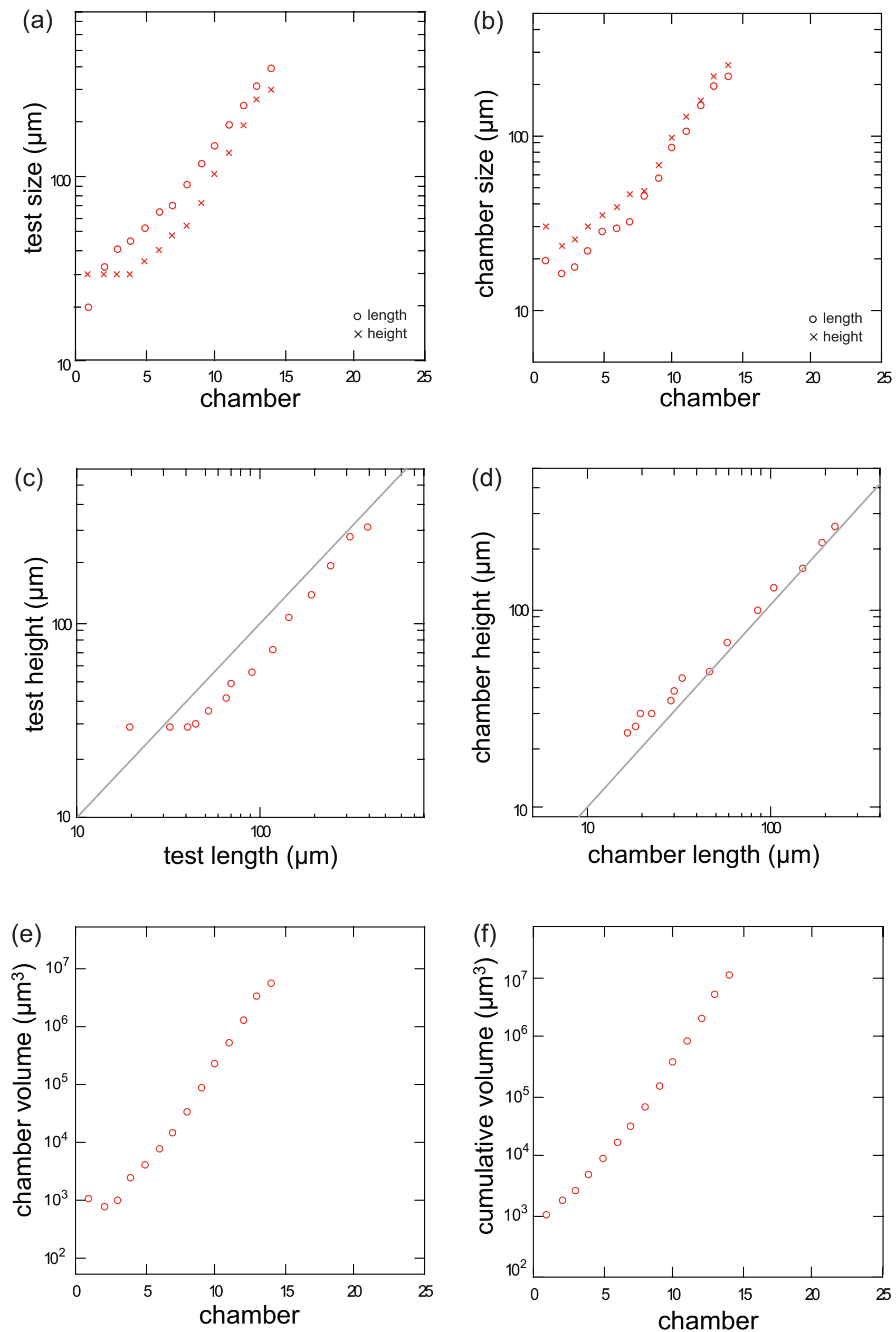

Fig. 1. Growth patterns of Globigerina bulloides. (a) Test and (b) chamber length and height versus chamber number; (c) test and (d) chamber height: length ratio (a 1:1 relationship is indicated by the grey line); (e) individual chamber and (f) cumulative test volume. 


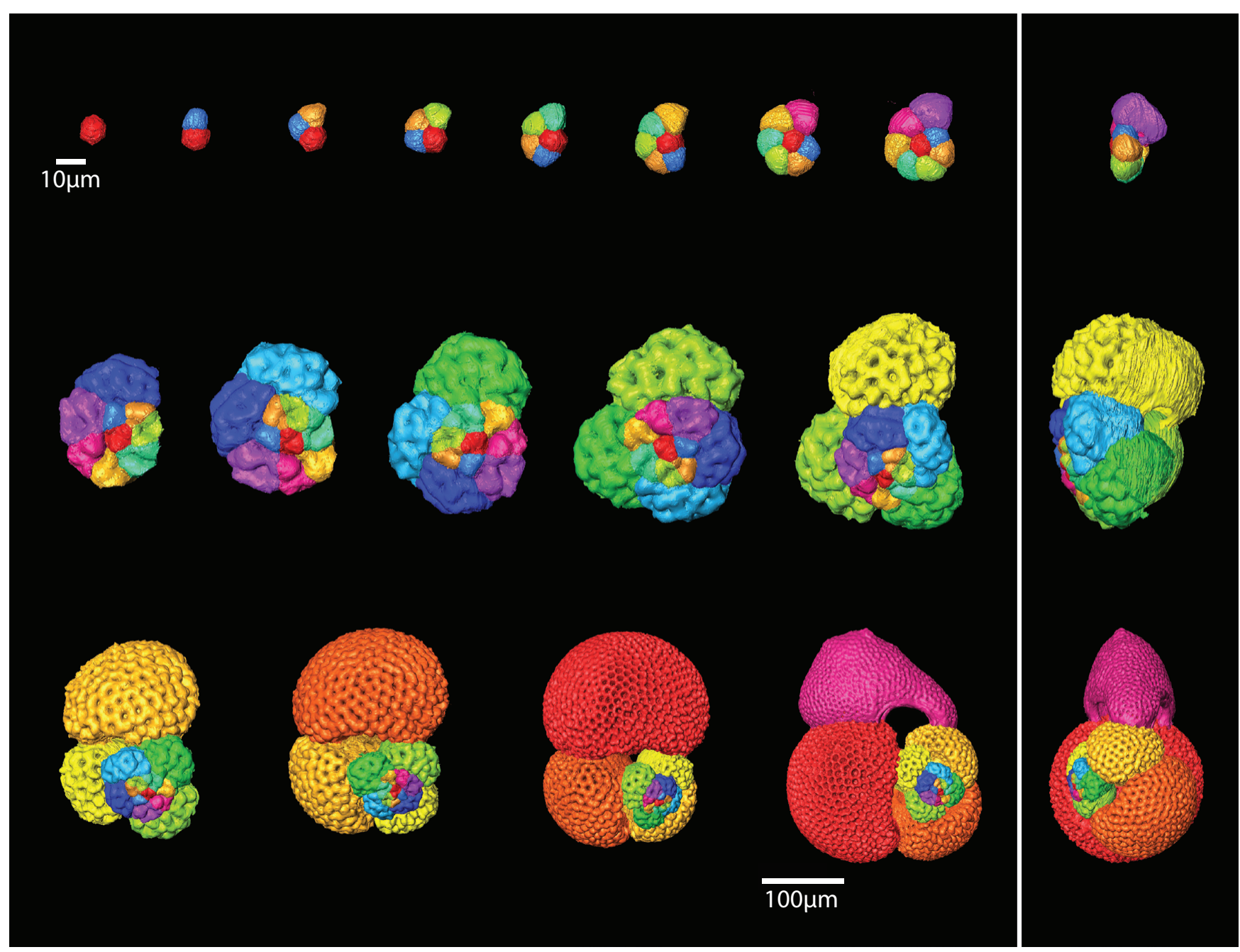

Explanation of Plate 2. 3D ontogenetic reconstruction of Globigerinoides sacculifer, 'sacculifer' morphotype from the proloculus (top left) to the terminal stage (bottom right).

$33 \mu \mathrm{m}$, and is followed by two smaller chambers. The blocky appearance of the chambers in the first whorl is due to the low scan resolution of $1.4 \mu \mathrm{m}$. Chambers appear to be subquadrate, spirally compressed and extending umbilically, and arranged in a very low trochospire. The overall shape outline is considerably more inflated on the umbilical side. The aperture is situated marginally. From chamber 6 , sutures between the successive chambers are recurved, indicating greater overlap during accretion. The chambers become increasingly subtriangular, leading to a low conical outline and the axial periphery becomes increasingly acute, culminating in a thin keel from the 8th chamber.

A gradual transition in morphology is operated from chamber 8, indicated by dorso-ventral compression of the chambers, as evidenced by the decrease in chamber height relative to chamber length (Fig. 4d); the subsequent transitional stage is considered equivalent to the neanic stage of spinose species. A wide umbilicus starts to develop and the spiral side of the test starts to curve slightly, progressing the overall shape to a distinctly lenticular outline. By chamber 12, a thick keel and a lip at the aperture have appeared, accompanied by a greater increase in chamber volume and a steepening of the length growth curves (Fig. 4a, b). These changes mark the adult stage of the individual.

Globorotalia tumida (Pl. 7). The specimen is composed of 21 chambers, starting with a near-spherical proloculus with a diameter of around $26 \mu \mathrm{m}$ and smaller deuteroconch. The juvenile stage is made up of subquadrate chambers inflated on the umbilical side; the overall test outline is consequently lobate. Successive chambers are arranged in a very low trochospiral, and recurved sutures point to a tighter coiling and greater overlap. A number of consecutive changes between chambers 8 and 12 marks the transitional neanic stage between the juvenile and adult stages. The rate of chamber volume expansion and chamber growth increases (Fig. 4). Chambers become increasingly angled on the umbilical side, resulting in a plano-convex outline and the gradual formation of a sharper axial periphery, which is established by the end of the neanic phase as chambers take on a subtriangular shape. The umbilicus is closed over, and the spiral side starts to curve, producing the adult lenticular test outline. Pustules are visible on the umbilical side from the 10th chamber.

The adult stage, from chamber 13, sees finalizing of the definitive shape, with chambers and overall test outline becoming increasingly compressed dorso-ventrally and length to height ratios increasing (Fig. 4c, d). A proto-keel present at chamber 13 takes on the typical thickened appearance in the final whorl. The aperture becomes thickened, gains a lip and elongates marginally to extend the whole of the chamber height. Fine pore pits become visible on the umbilical side; heavy secondary calcification obscures any trace of pores on the spiral side in all but the last three chambers. Whilst all other chambers maintain isometry in width to length in spiral view, the final two chambers are longer than wide, resulting in the upright shape characteristic of the species. 


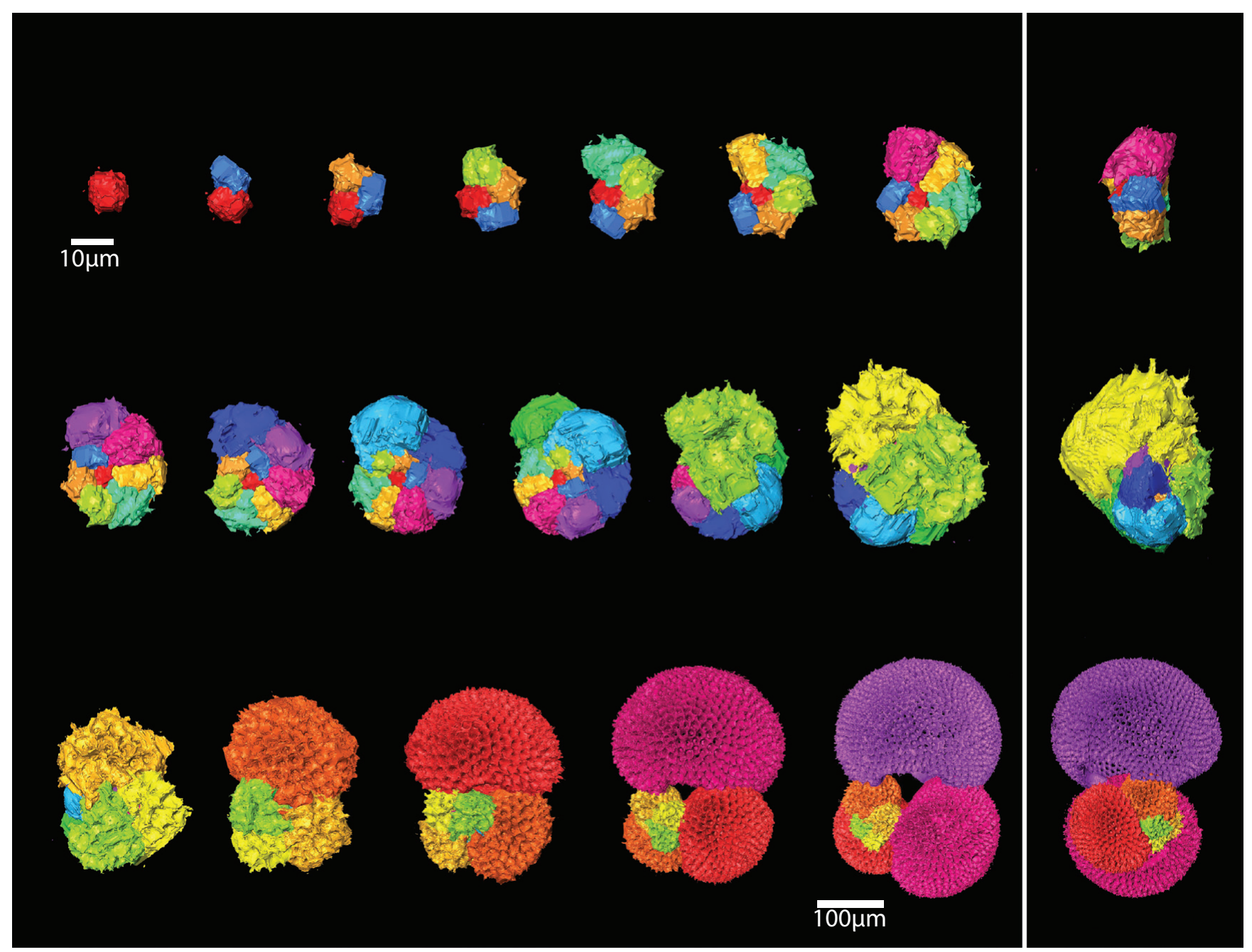

Explanation of Plate 3. 3D ontogenetic reconstruction of Globigerinoides sacculifer, 'trilobus' morphotype from the proloculus (top left) to the terminal stage (bottom right) (recoloured from Schmidt et al. 2013).

Globorotalia truncatulinoides (Pl. 8). The imaged specimen contains 17 chambers, growing from a large, spherical proloculus $30 \mu \mathrm{m}$ in diameter to a maximum length of $612 \mu \mathrm{m}$. The early chambers are subquadrate, with a slight spiral compression; by chamber 4 , chambers are additionally starting to angle on the umbilical side, creating a subtriangular chamber outline. Recurved sutures between successive chambers indicate greater overlap between them. The aperture is high-arched and rounded, and situated marginally. By the 7 th chamber, an acute periphery to the chambers and test forms as chambers become increasingly flattened on the spiral side and angled on the umbilical side. This leads to a planoconvex outline.

The neanic stage in spinose species begins at chamber 8 , when the rates of chamber length and height increase slow down (Fig. 5). The distinctly triangular test outline, characteristic of this species, has appeared, though the angle formed at the umbilicus is obtuse, with test length being greater than test height. This angle decreases as new chambers are added. Fine pores and short spines are visible on the umbilical side, and pores appear on the spiral side at chamber 10. A jump in chamber and test size and proportions at the 13th chamber marks the beginning of the adult stage (Fig. 5). A shift in chamber and overall test allometry results in a greater increase in chamber and test height relative to length, with the angle formed at the umbilicus becoming acute. In addition, the aperture has a thicker rim and becomes more elongate and low-arched, extending marginally along the entire height of the chamber. Growth is terminated in this specimen by the formation of a chamber of smaller dimensions, more thinly calcified, and with a finer surface texture.

\section{Discussion}

\section{Ontogenetic variation and growth}

The growth patterns in the ontogenetic models are different for the globigerinid and globorotaliid species, although a five-stage model as established by Brummer et al. (1987) can be applied for all species. A transitional neanic phase, where morphological features are gradually developed in a series of steps, can be identified between the morphologically conservative juvenile and adult stages in all specimens. In the globigerinid ontogeny, the onset of this neanic stage is marked by an increase in the incremental growth rate of the test as each new chamber is added, though the amount of change varies between species and specimens. The adult stage, however, appears as a continuation of these rates, with no clear demarcation from the neanic stage, as previously suggested by Brummer et al. (1987) and Hemleben et al. (1989). Identifying the adult phase in the globigerinids is species-specific and based on more qualitative criteria, such as the formation of a cancellate surface texture resulting from the development of spines and pores, the migration of the aperture to its terminal position, and features like secondary apertures. In the globorotaliid ontogeny, no such change occurs at the 

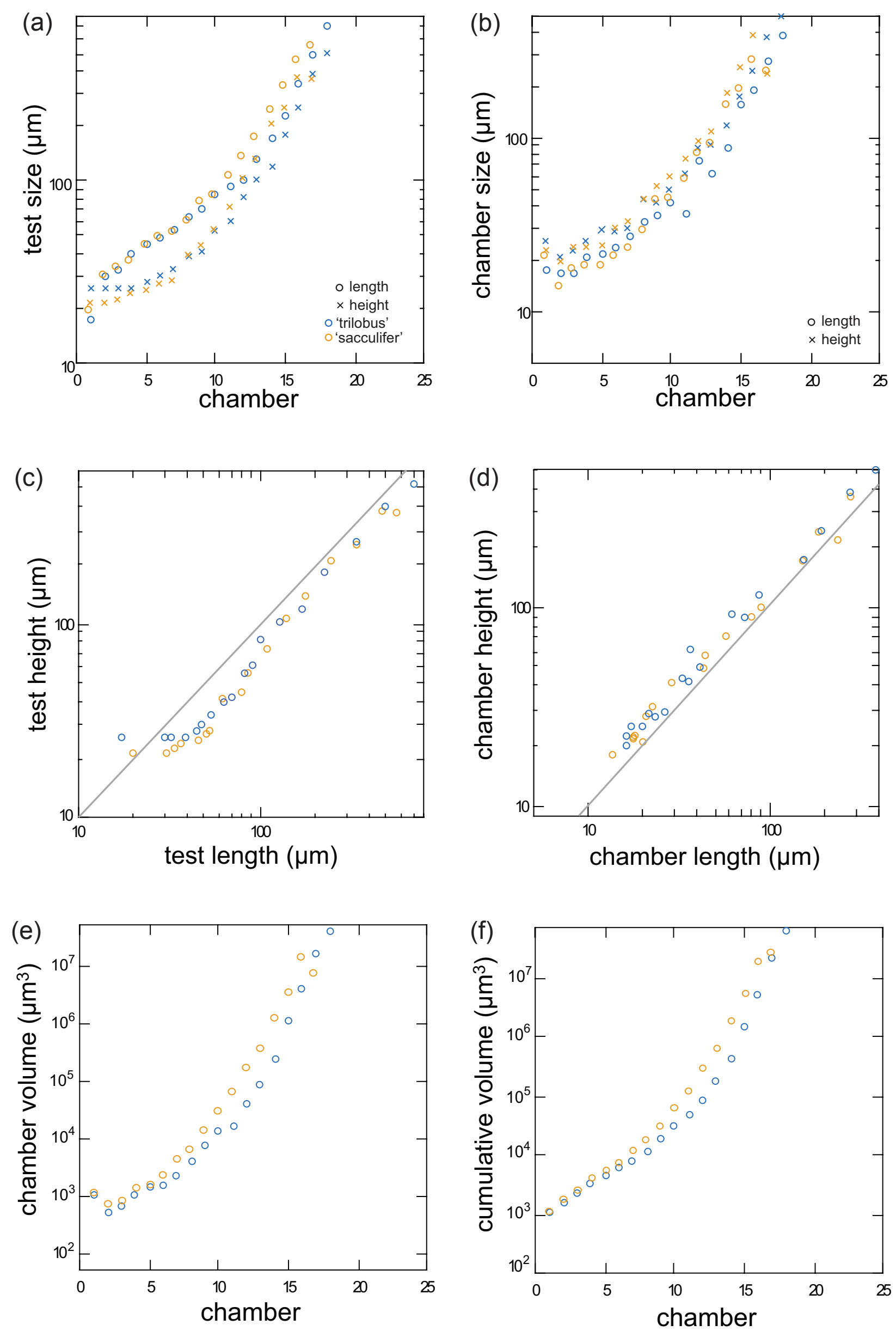

Fig. 2. Growth patterns of Globigerinoides sacculifer, 'sacculifer' and 'trilobus' morphotypes. (a) Test and (b) chamber length and height versus chamber number; (c) test and (d) chamber height: length ratio (a 1:1 relationship is indicated by the grey line); (e) individual chamber and (f) cumulative test volume. 


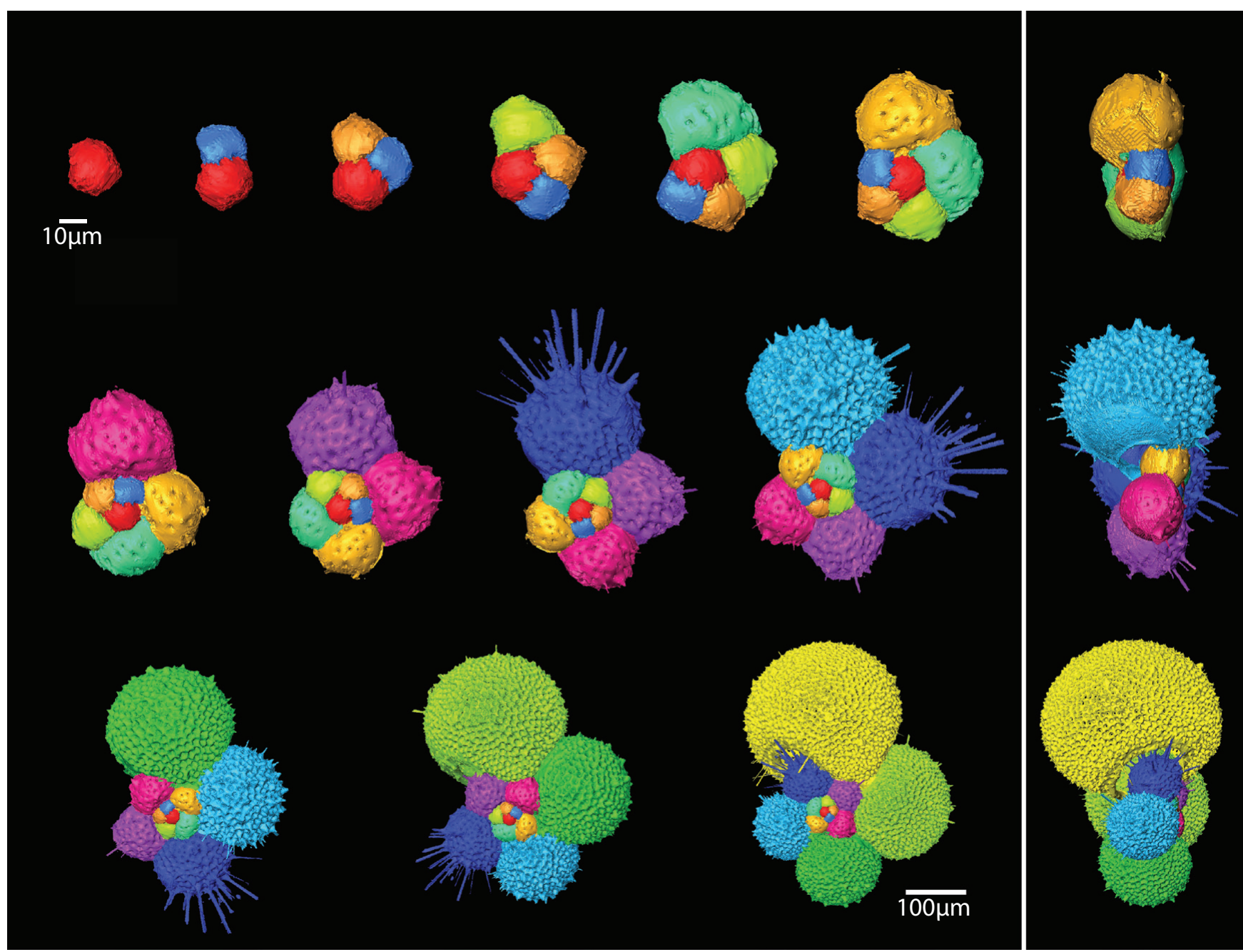

Explanation of Plate 4. 3D ontogenetic reconstruction of Globigerinella radians from the proloculus (top left) to the terminal stage (bottom right).

juvenile-to-neanic transition, which is recognized by the change in shape of the chambers.

As previously described by Schmidt et al. (2013), all species show exponential growth. While Schmidt et al. (2013) suggest a near-isometric trend in foraminiferal test and chamber dimensions across ontogeny based on Gd. trilobus and Gr. menardii, we observe a difference in allometric trends between the globigerinid and globorotaliid groups once more species are considered. The globigerinid species exhibit near-isometric growth of the chambers, while the test shows negative allometry in the juvenile stage followed by isometry or slightly positive allometry in the neanic and adult stages. As highlighted by Schmidt et al. (2013), this confirms the findings of the modelling studies by Signes et al. (1993) that the juvenile stages cannot follow a strict isometric arrangement if they are to maintain an exponential volumetric growth. In the globigerinids, species-specific characteristics, such as shape and coiling, usually considered to typify the adult stage, appear to be programmed from the outset of the neanic stage to remain within the same framework. Changes in test shape result predominantly from changes in the coiling pattern dictating where successive chambers are added on to the test.

In contrast, in the globorotaliid species the change in allometry occurs between the neanic and the adult stage. Chamber allometry is slightly negative and consistent in both juvenile and neanic stages while the adult stages depart from the trend. Globorotalia truncatulinoides is dorso-ventrally compressed in early ontogeny, as are the other globorotaliids. During its adult stage, it acquires the characteristic conical shape and umbilical expansion, producing isometric test and chambers (Fig. 5c, d). Similarly, in the final stages of $G r$. tumida and $G r$. menardii the chambers become negatively allometric, increasing length relative to height, while the test exhibits a consistent allometric trend throughout all stages of ontogeny. Allometry has previously been described in other globorotaliid and fohsellid species, such as Globorotalia inflata (Wei et al. 1992) and Globorotalia (Fohsella) fohsi (Olsson 1972, 1973). In the globorotaliids, species-specific shape characteristics seem dominated by chamber shape, with innovation restricted to the adult stages.

\section{Biotic and evolutionary implications}

Despite the differences in growth patterns between globigerinids and globorotaliids, the similarity in juvenile morphology across all species, being plano-convex globorotaliform regardless of the adult morphology, is striking, and suggests early ontogenetic constraints. It has been suggested that all macroperforate planktonic foraminifera since the end-Cretaceous mass extinction share a common ancestor with a globorotaliform morphology. Only two species survived into the Cenozoic (Olsson et al. 1999; Aze et al. 2011), both possessing this morphology, thus providing a possible phylogenetically inherited constraint on early ontogeny. As juvenile stages in all species appear to be herbivorous, and surfacedwelling in early ontogeny, with subsequent species-specific migration to greater depths with growth (Hemleben et al. 1989), this common morphology may represent an ecologically-driven constraint in juvenile stages. 

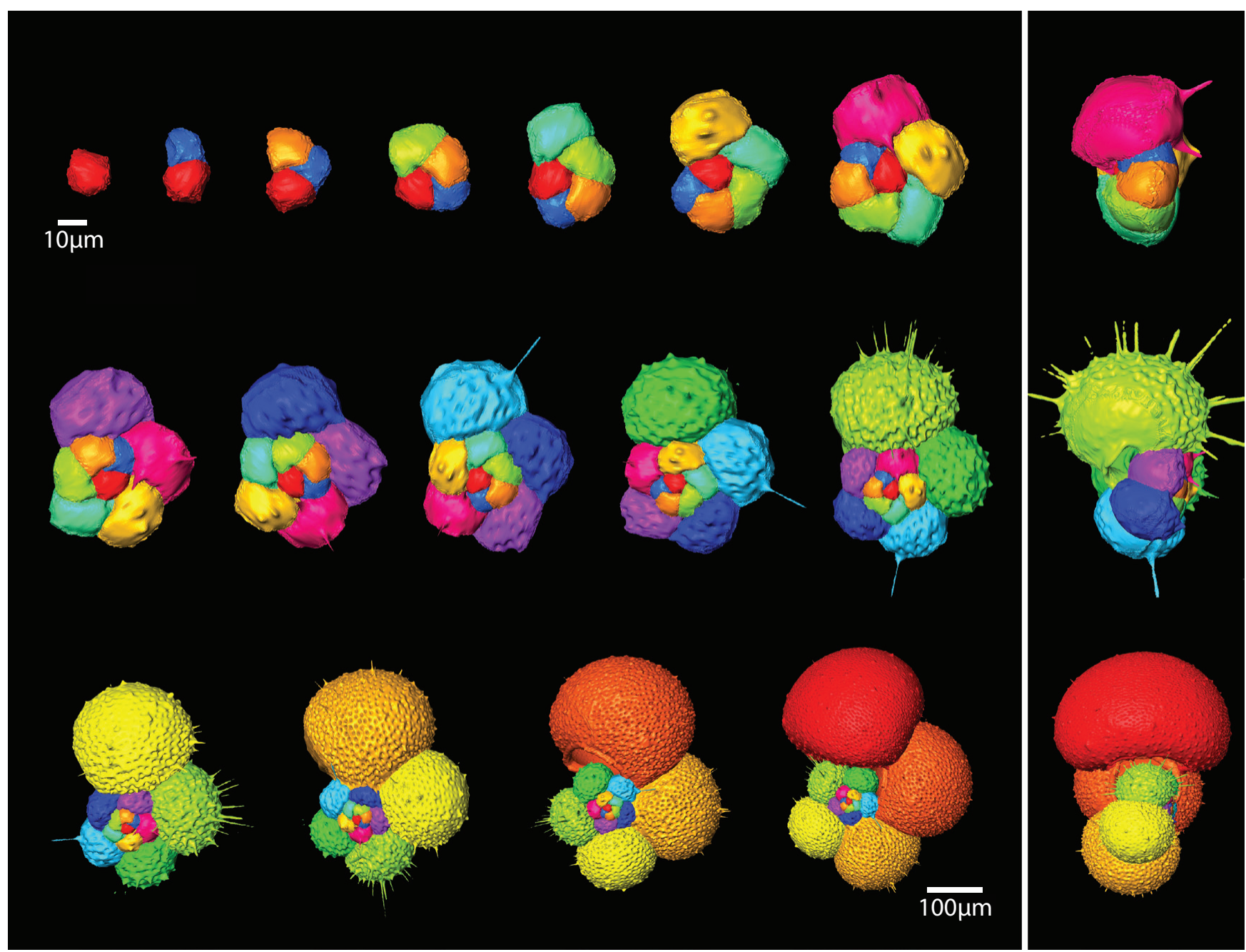

Explanation of Plate 5. 3D ontogenetic reconstruction of Globigerinella siphonifera from the proloculus (top left) to the terminal stage (bottom right).

\section{Biological constraints and ecological implications}

Changes in test morphology throughout ontogeny in all our investigated species result in a change in surface area to internal volume ratio (Fig. 6), which SRXTM allows us to investigate in planktic foraminifera for the first time. The test forms the template for the extrusion of the rhizopodial network and cytoplasm, while also containing the cytoplasm when it is retracted at night in some species (Hemleben et al. 1989). Surface area dictates the efficiency of processes involved in cell metabolism and growth, such as feeding and diffusion of nutrients, oxygen and carbonate ions (Signes et al. 1993). In addition, in symbiont-bearing species the surface area influences the distribution and abundance of symbionts. Volume relates to metabolic requirements and will likely define the amount of gametes produced, in the reproductive differentiation of the cytoplasm within the test (Bé et al. 1977). Surface area to volume ratios decrease for all species through ontogeny (Fig. 6), which would lead to an increase in metabolic requirements and a decrease in metabolic efficiency, requiring an increase in metabolic turnover in the adult.

In spinose species, surface area to volume ratios level out at test lengths of $100 \mu \mathrm{m}$. High early surface area to volume ratios characterize the juvenile stage of G. bulloides and the Gll. radians/Gll. siphonifera sister-taxa, whilst they also encompass the neanic stage in both $G d$. sacculifer specimens (Fig. 6). The change from the juvenile to neanic stages in the spinose species has been associated with a change in trophic behaviour, going from an algal and protozoan diet to a predominantly (though not exclusively) carnivorous diet (Hemleben et al. 1989). As seen above, this transition also corresponds to an increase in growth curves and in cytoplasm volume (Figs 1-3). Reaching a threshold size of $100 \mu \mathrm{m}$ could mark the ability to tackle larger prey, such as nauplii larvae, which would be more efficient for organisms that find their prey through chance encounters. Larger prey would also allow the foraminifer to meet the metabolic requirements for greater cytoplasm expansion and thus sustain higher growth rates leading to shorter life cycles (Hemleben et al. 1989), despite the decrease in metabolic efficiency. Whether this change in diet is necessary for survival to meet inherent changes in growth rates, or whether change in diet is purely opportunistic, thereby allowing growth rates to increase, is still unclear.

Surface area to volume ratios in adult Gr. menardii and Gr. tumida are similar to those of adult spinose species, which is counterintuitive given the flatter shape. Globorotalia truncatulinoides has comparatively lower ratios in the juvenile stages, but as the ratios decrease little they increase relative to other species throughout the neanic and adult stages. Non-spinose species are primarily herbivorous as adults (Hemleben et al. 1989), which in light of the trade-off between metabolic requirements and metabolic efficiency with growth, could explain their slower life cycles (Hemleben et al. 1989; Spear et al. 2011).

Evolutionary changes in shape within lineages have been argued to relate to changes in depth occupation or as a response to changes in watermass properties, through the influence of surface area to volume ratio on drag and settling (Malmgren \& Kennett 1981; 

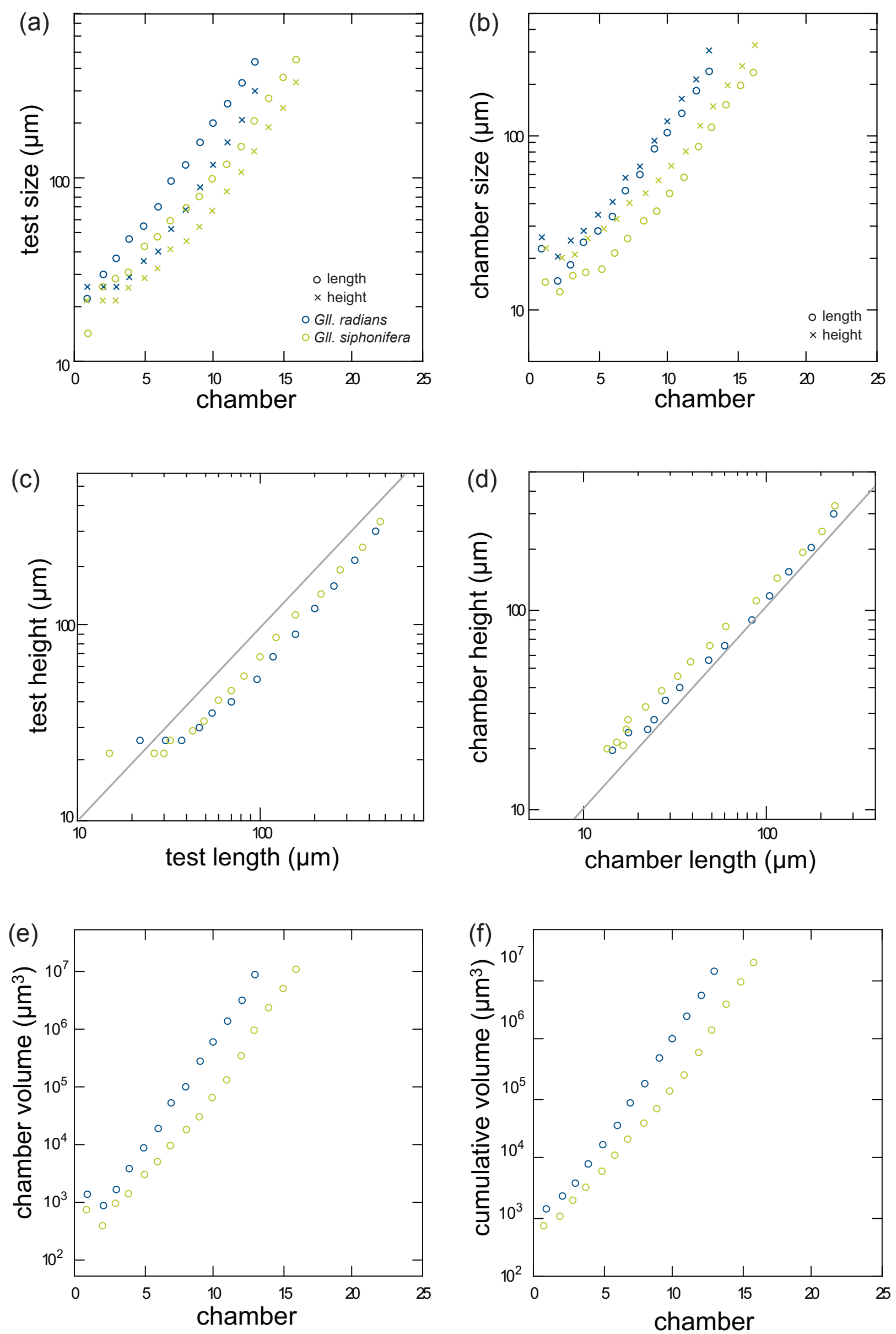

Fig. 3. Growth patterns of Globigerinella radians and Globigerinella siphonifera. (a) Test and (b) chamber length and height versus chamber number; (c) test and (d) chamber height: length ratio (a 1:1 relationship is indicated by the grey line); (e) individual chamber and (f) cumulative test volume. 

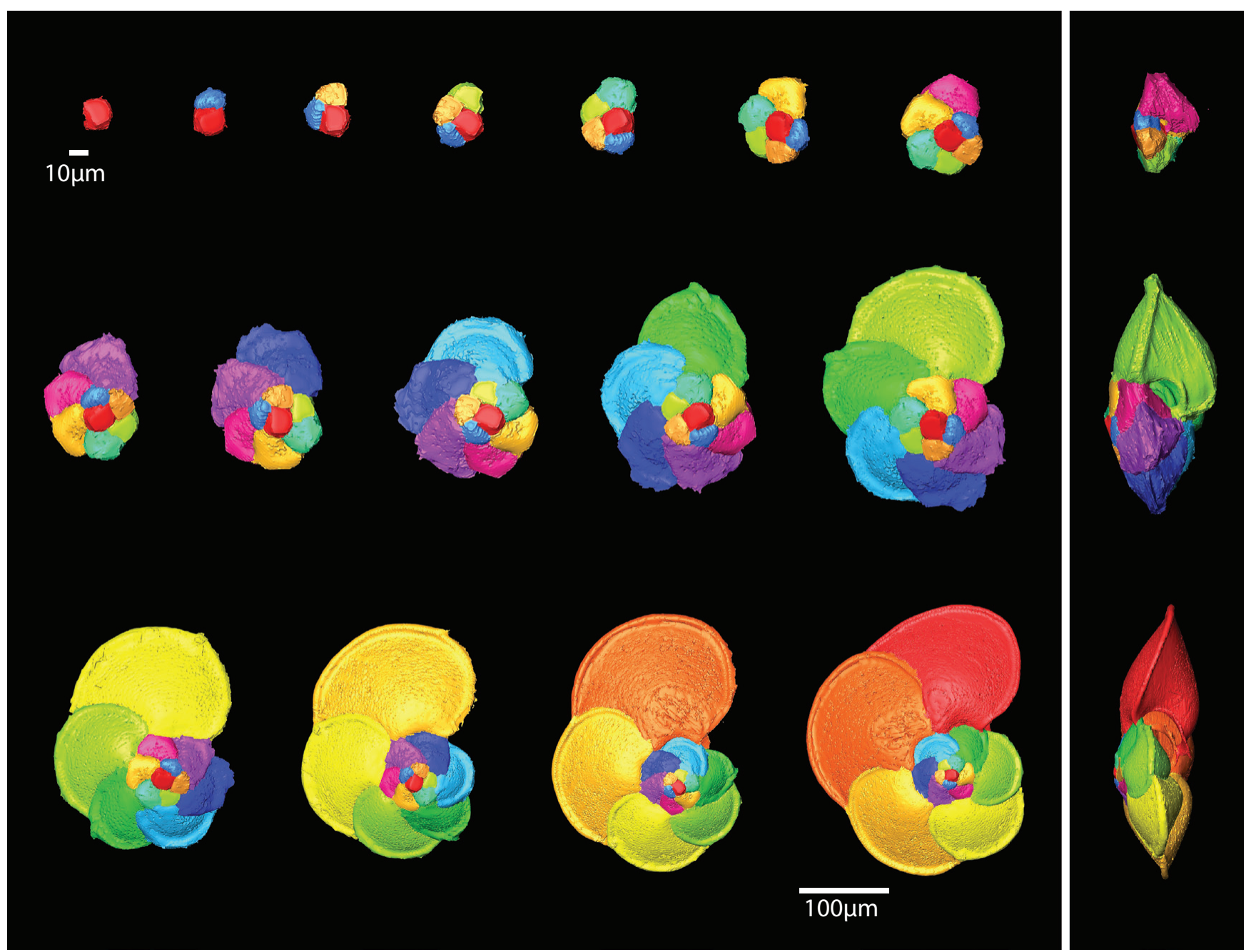

Explanation of Plate 6. 3D ontogenetic reconstruction of Globorotalia menardii from the proloculus (top left) to the terminal stage (bottom right) (recoloured from Schmidt et al. 2013).

Wei 1994; Schneider \& Kennett 1996). Not only has cryptic speciation shown that depth occupation does not necessarily entail significant morphological differentiation (de Vargas et al. 2002; Seears et al. 2012; Weiner et al. 2012), but neither size (Schmidt et al. 2006) nor shape (Caromel et al. 2014) seem to dictate specific habitat depth occupation. As has been suggested for phytoplankton (Falkowski \& Oliver 2007), we propose that any evolutionary changes in shape correlating with watermass properties will be driven by tertiary factors, such as prey availability, productivity, physiology and calcification, all of which will also co-vary with temperature, carbonate chemistry and salinity. For example, cell physiology accelerates with temperature, leading to faster growth and an increase in metabolic efficiency (see Schmidt et al. 2006 for a review), potentially allowing for a decrease in surface area. These tertiary factors will affect different stages of the ontogeny differently and will, therefore, influence the magnitude of their effect on evolutionary changes. Because of their comparatively greater surface area, juveniles are likely to be more vulnerable to factors which affect diffusion rates and metabolic efficiency. Neanic and adult stages will be more vulnerable to factors that will hinder meeting metabolic requirements for growth, such as food variability.

\section{Evolutionary implications}

Controlling metabolic requirements and onset of maturation and reproduction by delaying or accelerating transitions between stages presents a mechanism to generate variation and ultimately reproductive isolation and speciation. Considered to represent the earliest stages of speciation, different genotypes within cryptic species usually favour habitats with differing ecological properties (Huber et al. 1997; de Vargas et al. 2001; Renaud \& Schmidt 2003; Darling \& Wade 2008; Weiner et al. 2012). Ecological partitioning has recently been implicated in diversification within the planktic foraminifers (Weiner et al. 2012), with primary productivity as a principal variable (Seears et al. 2012). For example, genetic type I specimens of Gll. siphonifera, equivalent to Gll. radians (Weiner et al. 2015), favour shallow oligotrophic watermasses, while genetic type II specimens, true Gll. siphonifera (Weiner et al. 2015), inhabit more mesotrophic and eutrophic watermasses (de Vargas et al. 2002). Huber et al. (1997) showed in culturing experiments that genetic types I and II of Gll. siphonifera add new chambers at rates of 0.29 and 0.4 chambers/day, respectively, under identical culture conditions. Using these chamber formation rates to convert our results in terms of days shows that the Gll. siphonifera specimen reaches maturity faster despite the greater number of chambers added (Fig. 7). The onset of the neanic stage in both specimens occurs at similar size while the Gll. siphonifera specimen reaches adult stage at a smaller overall test length, implying an earlier onset of adult characteristics, or acceleration in the rate of development in the Gll. siphonifera specimen. This supports the idea of a threshold size for the onset of chamber shape changes at the neanic stage relating to metabolic processes, as an acceleration once this size threshold is reached is compatible with the suggested faster metabolism in Gll. siphonifera resulting 

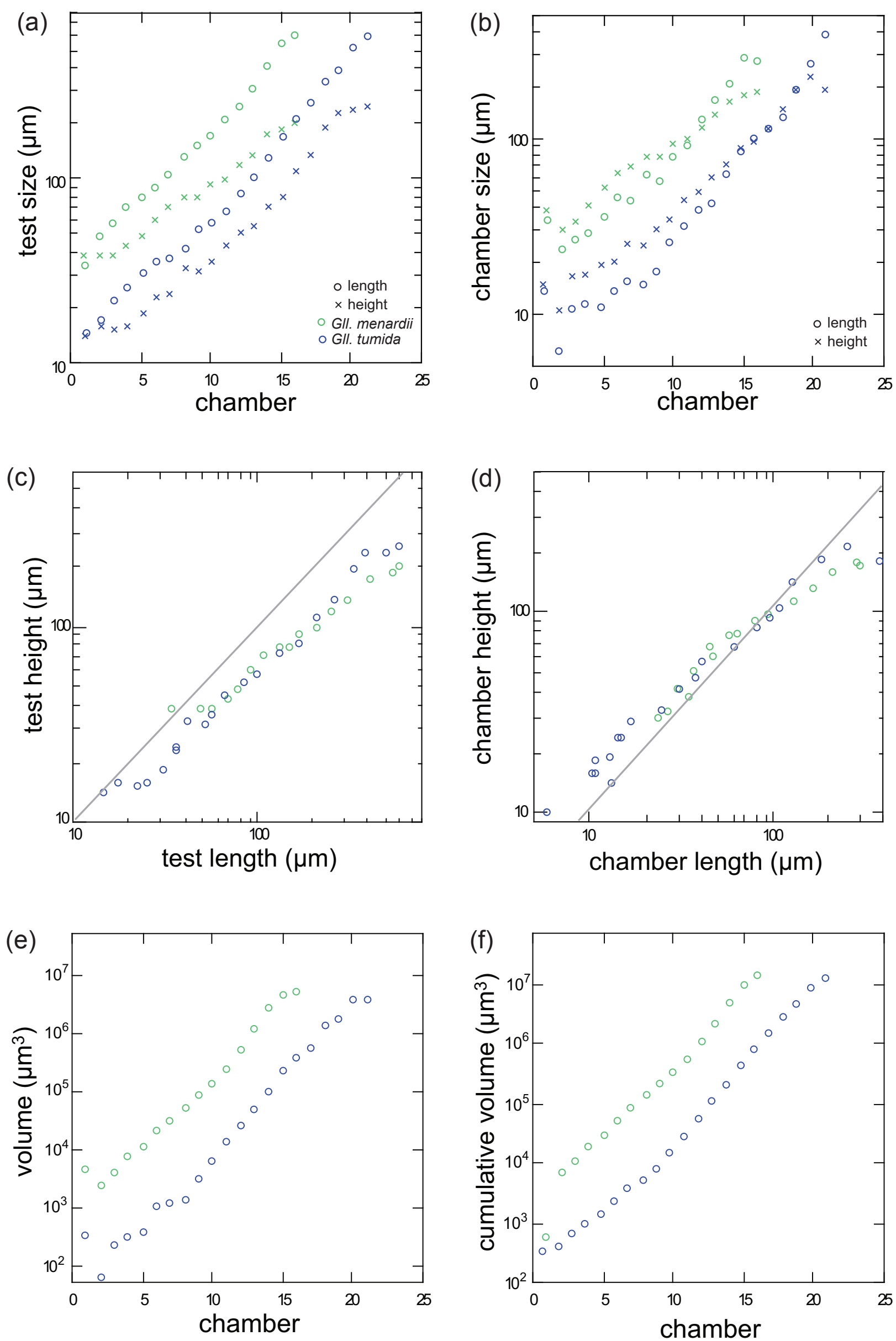

Fig. 4. Growth patterns of Globorotalia menardii and Globorotalia tumida. (a) Test and (b) chamber length and height versus chamber number; (c) test and (d) chamber height: length ratio (a 1:1 relationship is indicated by the grey line); (e) individual chamber and (f) cumulative test volume. 


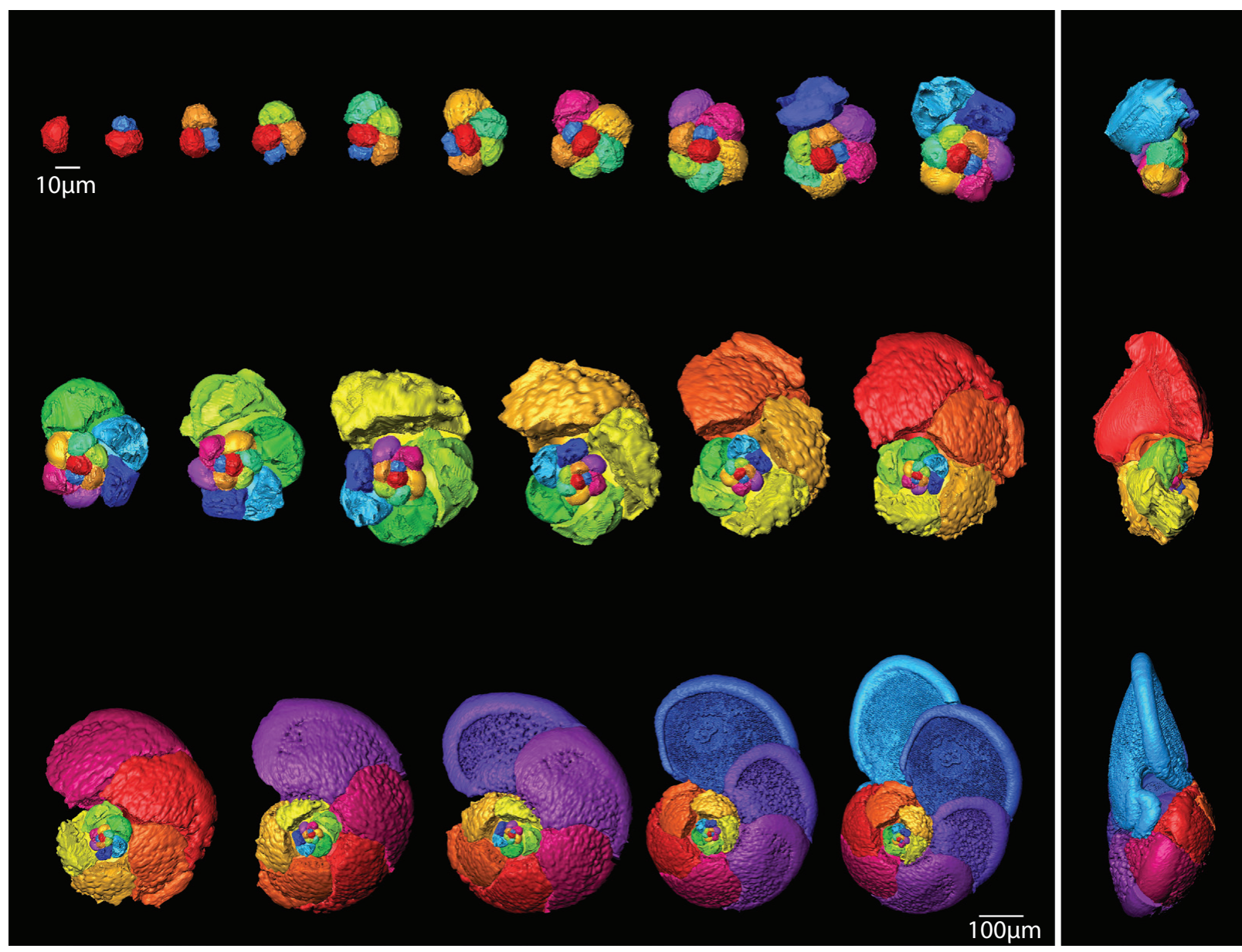

Explanation of Plate 7. 3D ontogenetic reconstruction of Globorotalia tumida from the proloculus (top left) to the terminal stage (bottom right).

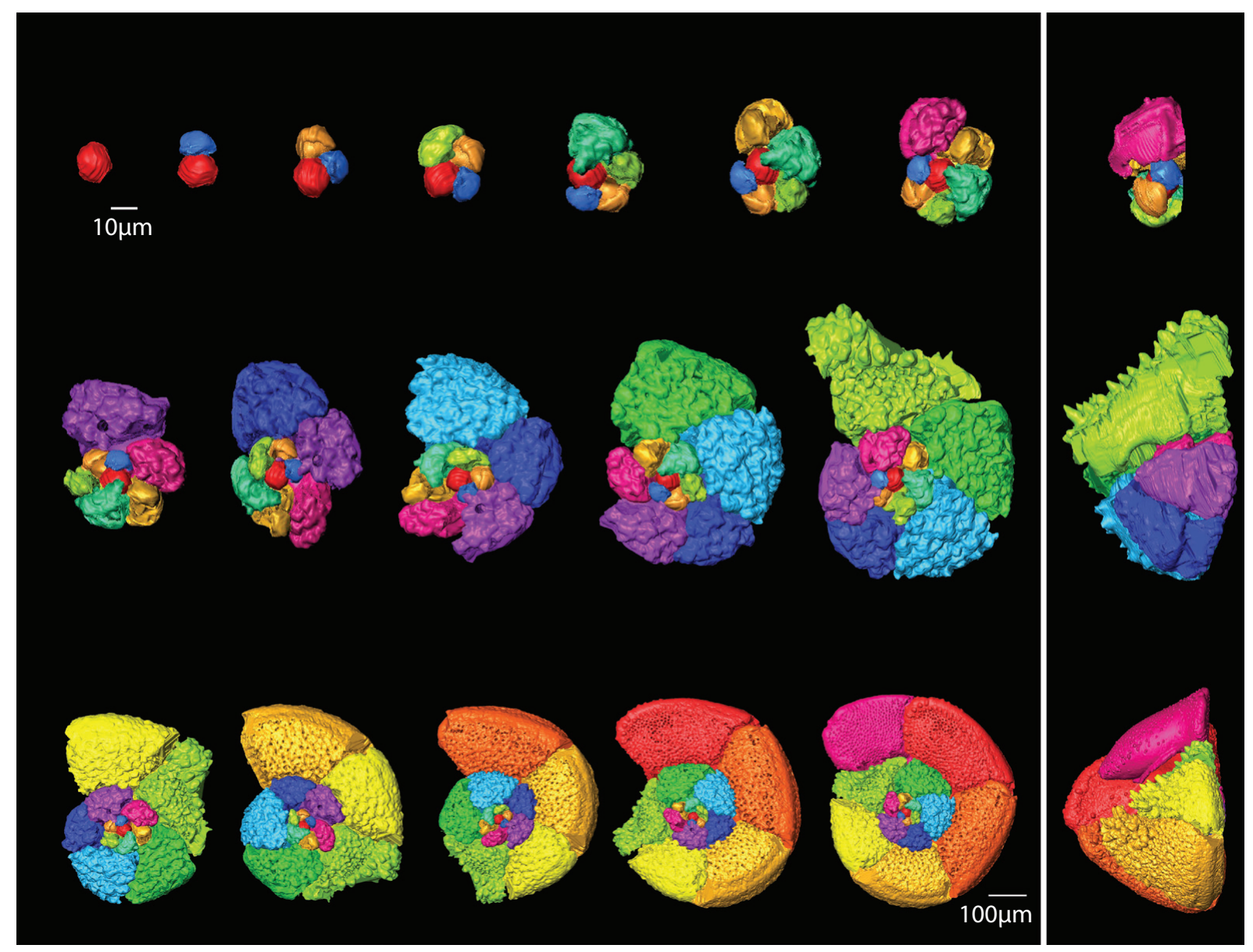

Explanation of Plate 8. 3D ontogenetic reconstruction of Globorotalia truncatulinoides from the proloculus (top left) to the terminal stage (bottom right) 

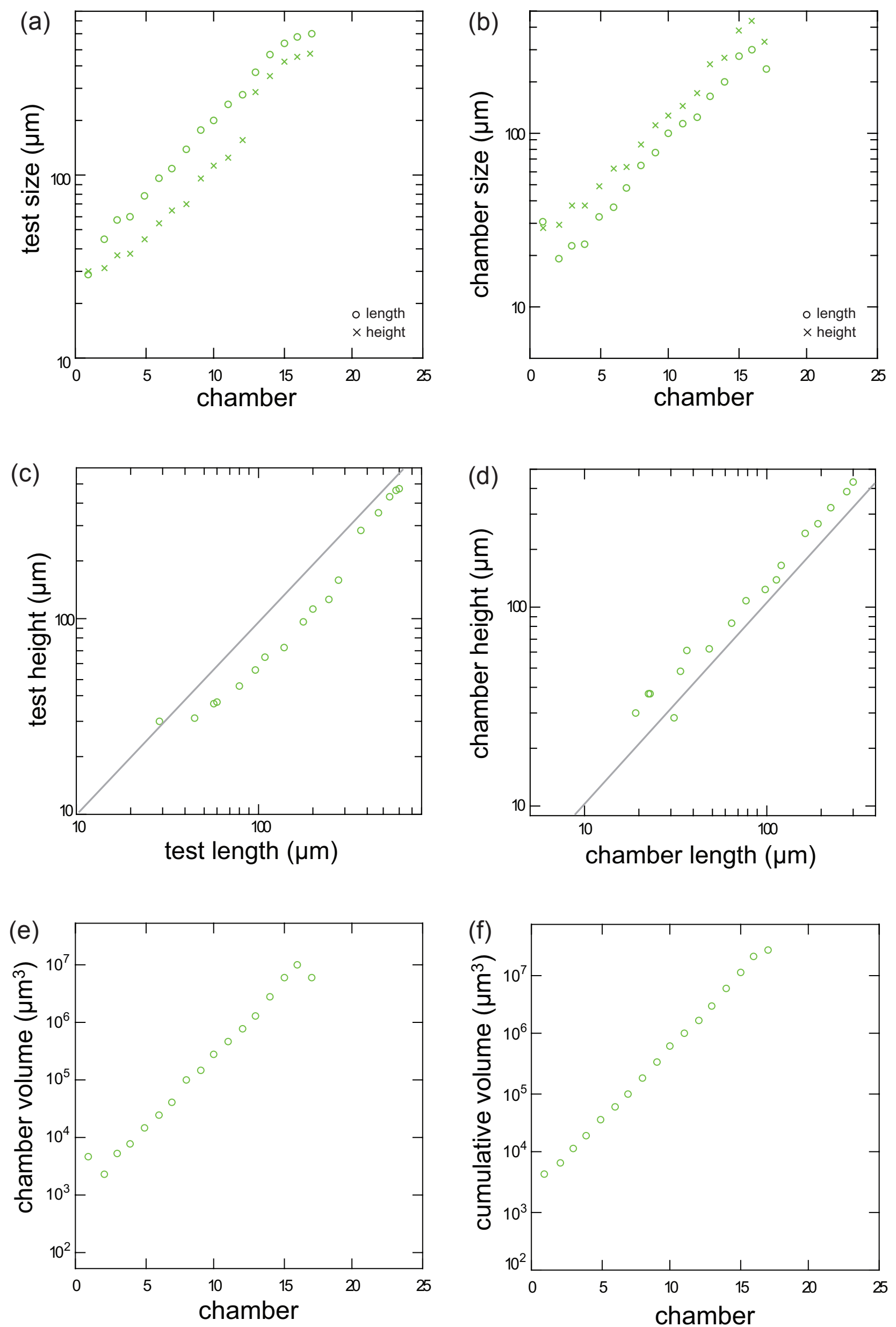

Fig. 5. Growth patterns of Globorotalia truncatulinoides. (a) Test and (b) chamber length and height versus chamber number; (c) test and (d) chamber height: length ratio (a 1:1 relationship is indicated by the grey line); (e) individual chamber and (f) cumulative test volume. 


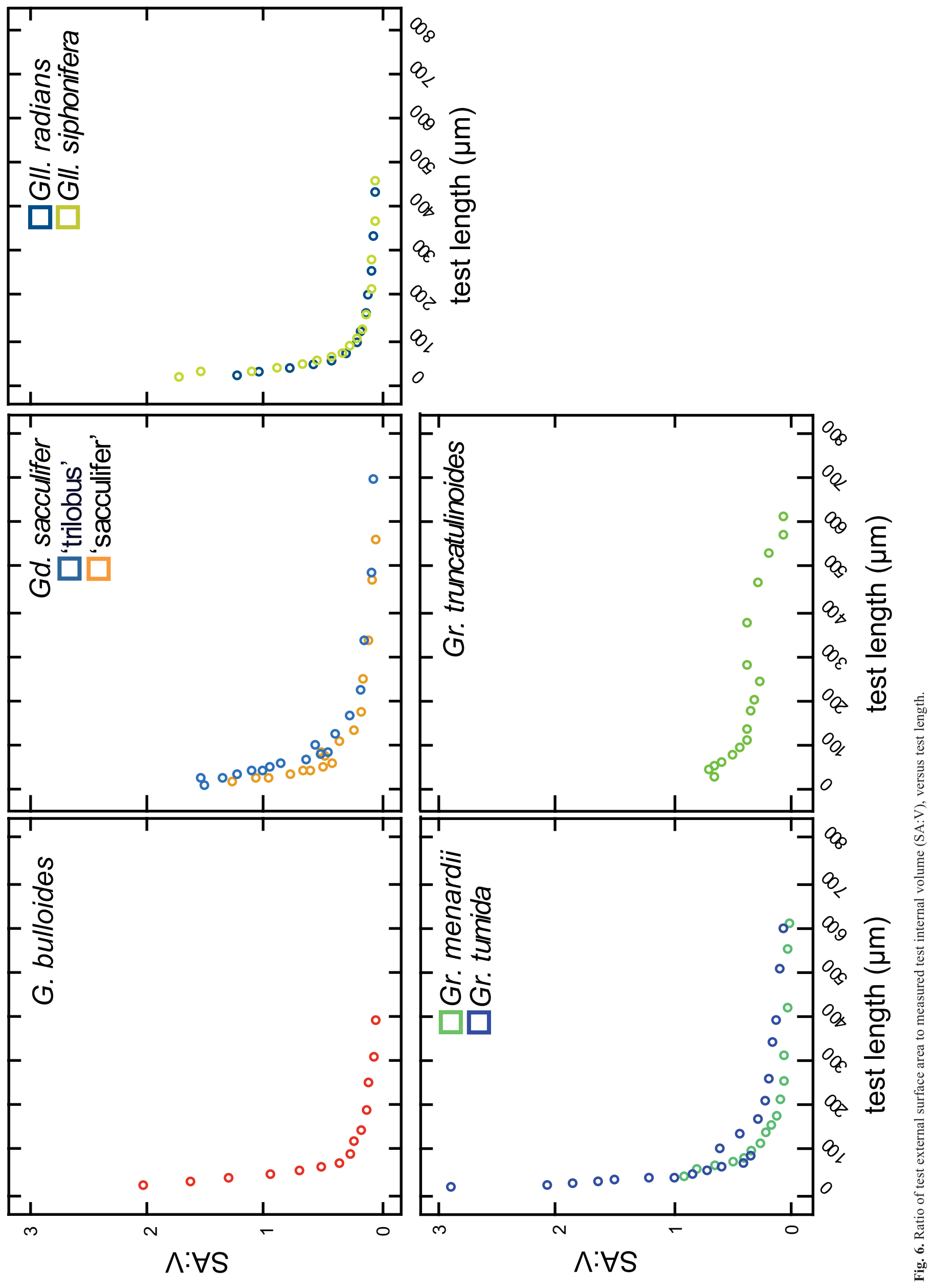




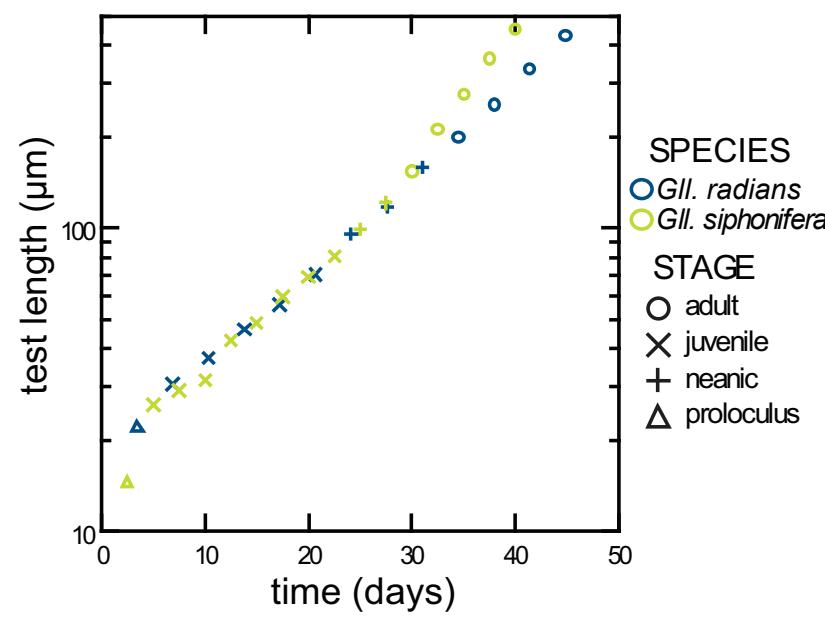

Fig. 7. Test length versus time, using chamber formation rates from Huber et al. (1997), for Globigerinella siphonifera and Globigerinella radians.

from greater prey availability in eutrophic areas. The slower metabolism and longer survival of Gll. radians specimens have been suggested to make this type better adapted to the shallow oligotrophic watermasses (de Vargas et al. 2002).

Comparing the chamber formation and metabolic rates for the Gll. siphonifera complex derived from artificial and optimal laboratory conditions does not take their different habitats into account, which could undoubtedly lead to different feeding regimes and consequently affect chamber formation rates. Nevertheless, culturing experiments of other species under different feeding regimes have shown that food deprivation, within the limits of species' tolerance, results in slower growth and a longer life, possibly extending survival of the organism until conditions become favourable enough for reproduction and maximal survival of the young (Hemleben et al. 1989). Sverdlove \& Bé (1985) reported that greater proloculus size is related to higher surface water productivity, and specimens with larger proloculi add fewer chambers to reach the specific sizes at which ontogenetic stage transitions occur (Brummer et al. 1987). Some plasticity in growth patterns and in the rates of chamber formation needs to exist to account for food variability and for ecophenotypic variation in general. Consequently, the ontogenetic analysis of more specimens of the selected species, as well as a more comprehensive sampling of the species and morphological diversity, is required in future to further support the trends identified in this paper.

\section{Conclusion}

Differences in growth patterns can be identified between the ontogenies of the globigerinid and globorotaliid species studied. In the globigerinids, species grow isometrically from the outset of the neanic stage, when the dominant morphological changes occur. Morphological change seems governed by changes in the accretion pattern. In contrast, in the globorotaliids, innovation appears possible through allometric changes in chamber proportions, but is restricted to the adult stages, and species-specific shape characters are governed by chamber shape.

Changes in surface area to volume ratios through ontogeny due to changes in morphology will lead to differences in metabolic requirements and processes during growth. Environmental influences on evolutionary processes may thus be driven by different factors affecting different stages of ontogeny; juveniles, with higher surface area to volume ratios, would be more vulnerable to changes in diffusion rates, whereas adults may be more affected by difficulties in meeting metabolic demands. These considerations will delimit the scope of action of evolutionary mechanisms such as heterochrony.

\section{Acknowledgements and Funding}

The authors would like to thank Alex Cocking for assistance in the reconstruction of Gr. menardii and Gd. trilobus. Thanks to Phil Donoghue and Michal Kucera for discussion and comments on an earlier version of the manuscript, and to Paul Pearson and Manuel Weinkauf for their thorough reviews and suggestions for improvement. Thanks to Brian Huber for providing the Gll. siphonifera and Gll. radians specimens. AGMC was funded by a Natural Environmental Research Council studentship (NE/G524228/1). DNS acknowledges the support of The Royal Society in the form of a University Research Fellowship. The Swiss Light Source at the Paul Scherrer Institute, Villigen, is thanked for beamtime access and support under proposals 20060780 and 20090840/20090843(merged). The raw data are archived on PANGAEA at http://doi.pangaea.de/10.1594/ PANGAEA.841251 This paper is a contribution to SCOR Working Group 138. Colour for the print version of this paper was funded by a grant from The Micropalaeontological Society.

\section{Scientific editing by Sigal Abramovich}

\section{References}

Alberch, P., Gould, S.J., Oster, G.F. \& Wake, D.B. 1979. Size and shape in ontogeny and phylogeny. Paleobiology, 5, 296-317.

Aze, T., Ezard, T.H.G., Purvis, A., Coxall, H.K., Stewart, D.R.M., Wade, B.S. \& Pearson, P.N. 2011. A phylogeny of Cenozoic macroperforate planktonic foraminifera from fossil data. Biological Reviews, 86, 900-927.

Bé, A.W.H. \& Lott, L. 1964. Shell growth and structure of planktonic Foraminifera. Science, 145, 823-824.

Bé, A.W.H., Jongebloed, W.L. \& McIntyre, A. 1969. X-ray microscopy of recent planktonic Foraminifera. Journal of Paleontology, 43, 1384-1396.

Bé, A.W.H., Hemleben, C., Anderson, O.R., Spindler, M., Hacunda, J. \& Tuntivate-Choy, S. 1977. Laboratory and field observations of living planktonic foraminifera. Micropaleontology, 23, 155-179.

Bé, A.W.H., Caron, D.A. \& Anderson, O.R. 1981. Effects of feeding frequency on life processes of the planktonic foraminifer Globigerinoides sacculifer in laboratory culture. Journal of the Marine Biological Association of the United Kingdom, 61, 257-277.

Bijma, J., Faber, W.W. \& Hemleben, C. 1990. Temperature and salinity limits for growth and survival of some planktonic foraminifers in laboratory cultures. Journal of Foraminiferal Research, 20, 95-116.

Brummer, G.J.A., Hemleben, C. \& Spindler, M. 1986. Planktonic foraminifera ontogeny and new perspectives for micropaleontology. Nature, 319, 50-52.

Brummer, G.J.A., Hemleben, C. \& Spindler, M. 1987. Ontogeny of extant spinose planktonic foraminifera (Globigerinidae): A concept exemplified by Globigerinoides sacculifer (Brady) and G. ruber (D'Orbigny). Marine Micropaleontology, 12, 357-381.

Caromel, A.G.M., Schmidt, D.N., Rayfield, E.J. \& Phillips, J.C. 2014 Hydrodynamic constraints on the evolution and ecology of planktic foraminifera. Marine Micropaleontology, 106C, 69-78, http://doi.org/10.1016/j. marmicro.2014.01.002

Darling, K.F. \& Wade, C.M. 2008. The genetic diversity of planktic foraminifera and the global distribution of ribosomal RNA genotypes. Marine Micropaleontology, 67, 216-238.

Darling, K.F., Wade, C.M., Kroon, D., Brown, A.J.L. \& Bijma, J. 1999. The diversity and distribution of modern planktic foraminiferal small subunit ribosomal RNA genotypes and their potential as tracers of present and past ocean circulations. Paleoceanography, 14, 3-12.

de Vargas, C., Renaud, S., Hilbrecht, H. \& Pawlowski, J. 2001. Pleistocene adaptive radiation in Globorotalia truncatulinoides: Genetic, morphologic, and environmental evidence. Paleobiology, 27, 104-125.

de Vargas, C., Bonzon, M., Rees, N.W., Pawlowski, J. \& Zaninetti, L. 2002. A molecular approach to biodiversity and biogeography in the planktonic foraminifer Globigerinella siphonifera (d'Orbigny). Marine Micropaleontology, 45, 101-116.

Donoghue, P.C.J., Bengtson, S. et al. 2006. Synchrotron X-ray tomographic microscopy of fossil embryos. Nature, 442, 680-683.

Falkowski, P.G. \& Oliver, M.J. 2007. Mix and match: How climate selects phytoplankton. Nature Reviews Microbiology, 5, 813-819.

Gerber, S., Eble, G.J. \& Neige, P. 2008. Allometric space and allometric disparity: A developmental perspective in the macroevolutionary analysis of morphological disparity. Evolution, 62, 1450-1457, http://doi.org/10.1111/ j.1558-5646.2008.00370.x

Healy-Williams, N. 1989. Morphological changes in living foraminifera and the thermal structure of the water column, Western North Atlantic. Palaios, 4, 590-597.

Hecht, A.D. 1974. Intraspecific variation in Recent populations of Globigerinoides ruber and Globigerinoides trilobus and their application to paleoenvironmental analysis. Journal of Paleontology, 48, 1217-1234.

Hecht, A.D. \& Savin, S.M. 1972. Phenotypic variation and oxygen isotope ratios in Recent planktonic foraminifera. Journal of Foraminiferal Research, 2, 55-67.

Hemleben, C., Breitinger, O. \& Ott, R. 1987. Morphological and physiological responses of Globigerinoides sacculifer (Brady) under varying laboratory conditions. Marine Micropaleontology, 12, 305-324.

Hemleben, C., Spindler, M. \& Anderson, O.R. 1989. Modern Planktonic Foraminifera. Springer, New York. 
Huang, C.-Y. 1981. Observations on the interior of some late Neogene planktonic foraminifera. Journal of Foraminiferal Research, 11, 173-190.

Huber, B.T. 1994. Ontogenetic morphometrics of some Late Cretaceous trochospiral planktonic Foraminifera from the Austral Realm. Smithsonian Contributions to Paleobiology, 77, 1-85.

Huber, B.T., Bijma, J. \& Darling, K. 1997. Cryptic speciation in the living planktonic foraminifer Globigerinella siphonifera. Paleobiology, 23, 33-62.

Hutchinson, G.E. 1961. The paradox of the plankton. American Naturalist, 95, $137-145$.

Lipps, J.H. 1973. Test structure in Foraminifera. Annual Reviews in Microbiology, 27, 471-486.

Malmgren, B.A. \& Kennett, J.P. 1981. Phyletic gradualism in a Late Cenozoic planktonic foraminiferal lineage; DSDP Site 284, Southwest Pacific. Paleobiology, 7, 230-240.

Norris, R.D. 2000. Pelagic species diversity, biogeography, and evolution. Paleobiology, 26, 236-258.

Olsson, R.K. 1972. Growth changes in the Globorotalia fohsi lineage. Eclogae Geologicae Helvetiae, 65, 165-184.

Olsson, R.K. 1973. Growth studies on Globorotalia exilis Blow and Globorotalia pertenuis Beard in the Hole 154A Section, Leg 15, Deep Sea Drilling Project. Initial Reports, Deep Sea Drilling Project, 15. US Government Printing Office, Washington, DC, 617-624.

Olsson, R.K., Berggren, W.A., Hemleben, C. \& Huber, B.T. 1999. Atlas of Paleocene Planktonic foraminifera. Smithsonian Contributions to Paleobiology. Smithsonian Institution Press, Washington, DC.

Palumbi, S.R. 1994. Genetic divergence, reproductive isolation, and marine speciation. Annual Review of Ecology and Sytematics, 25, 547-572.

Renaud, S. \& Schmidt, D.N. 2003. Habitat tracking as a response of the planktic foraminifer Globorotalia truncatulinoides to environmental fluctuations during the last 140 kyr. Marine Micropaleontology, 49, 97-122.

Roy, S. \& Chattopadhyay, J. 2007. Towards a resolution of 'the paradox of the plankton': A brief overview of the proposed mechanisms. Ecological Complexity, 4, 26-33.

Schlichting, C.D. \& Smith, H. 2002. Phenotypic plasticity: Linking molecular mechanisms with evolutionary outcomes. Evolutionary Ecology, 16, 189-211.

Schmidt, D.N., Renaud, S., Bollmann, J., Schiebel, R. \& Thierstein, H.R. 2004 Size distribution of Holocene planktic foraminifer assemblages: Biogeography, ecology and adaptation. Marine Micropaleontology, 50, 319-338.
Schmidt, D.N., Lazarus, D., Young, J.R. \& Kucera, M. 2006. Biogeography and evolution of body size in marine plankton. Earth-Science Reviews, $\mathbf{7 8}$ 239-266.

Schmidt, D.N., Rayfield, E.J., Cocking, A. \& Marone, F. 2013. Linking evolution and development: Synchrotron radiation X-ray tomographic microscopy of planktic foraminifers. Palaeontology, 56, 741-749.

Schneider, C.E. \& Kennett, J.P. 1996. Isotopic evidence for interspecies habitat differences during evolution of the Neogene planktonic foraminiferal clade Globoconella. Paleobiology, 22, 282-303.

Seears, H.A., Darling, K. \& Wade, B.S. 2012. Ecological partitioning and diversity in tropical planktonic foraminifera. BMC Evolutionary Biology, 12, 54, http://doi.org/10.1186/1471-2148-12-54.

Signes, M., Bijma, J., Hemleben, C. \& Ott, R. 1993. A model for planktic foraminiferal shell growth. Paleobiology, 19, 71-91.

Spear, J.W., Poore, R.Z. \& Quinn, T.M. 2011. Globorotalia truncatulinoides (dextral) $\mathrm{Mg} / \mathrm{Ca}$ as a proxy for Gulf of Mexico winter mixed-layer temperature: Evidence from a sediment trap in the northern Gulf of Mexico. Marine Micropaleontology, 80, 53-61.

Speijer, R.P., Van Loo, D., Masschaele, B., Vlassenbroeck, J., Cnudde, V. \& Jacobs, P. 2008. Quantifying foraminiferal growth with high-resolution $\mathrm{X}$-ray computed tomography: New opportunities in foraminiferal ontogeny, phylogeny and paleoceanographic applications. Geosphere, 4, 760-763.

Stampanoni, M., Groso, A. et al. 2006. Trends in synchrotron-based tomographic imaging: The SLS experience. Developments in X-Ray Tomography $V, \mathbf{6 3 1 8}, 1-14$, http://doi.org/10.1117/12.679497

Sverdlove, M.S. \& Bé, A.W.H. 1985. Taxonomic and ecological significance of embryonic and juvenile planktonic foraminifera. Journal of Foraminiferal Research, 15, 235-241.

Wei, K.-Y. 1994. Allometric heterochrony in the Pliocene-Pleistocene planktic foraminiferal clade Globoconella. Paleobiology, 20, 66-84

Wei, K.-Y., Zhang, Z.-W. \& Wray, C. 1992. Shell ontogeny of Globorotalia inflata (I): Growth dynamics and ontogenetic stages. Journal of Foraminiferal Research, 2, 318-327.

Weiner, A., Aurahs, R., Kurasawa, A., Kitazato, H. \& Kucera, M. 2012. Vertical niches partitioning between cryptic sibling species of a cosmopolitan marine planktonic protist. Molecular Ecology, 21, 4063-4073.

Weiner, A.K.M., Weinkauf, M.F.G., Kurasawa, A., Darling, K. \& Kucera, M. 2015. Genetic and morphometric evidence for parallel evolution of the Globigerinella calida morphotype. Marine Micropaleontology, 114, 19-35. 